\title{
Failure Mechanism of Rock Bridge Based on Acoustic Emission Technique
}

\author{
Guoqing Chen, Yan Zhang, Runqiu Huang, Fan Guo, and Guofeng Zhang \\ State Key Laboratory of Geohazard Prevention and Geoenvironment Protection, Chengdu University of Technology, Chengdu, \\ Sichuan 610059, China \\ Correspondence should be addressed to Guoqing Chen; chgq1982@126.com
}

Received 17 October 2014; Revised 23 December 2014; Accepted 7 January 2015

Academic Editor: Fei Dai

Copyright (c) 2015 Guoqing Chen et al. This is an open access article distributed under the Creative Commons Attribution License, which permits unrestricted use, distribution, and reproduction in any medium, provided the original work is properly cited.

Acoustic emission (AE) technique is widely used in various fields as a reliable nondestructive examination technology. Two experimental tests were carried out in a rock mechanics laboratory, which include (1) small scale direct shear tests of rock bridge with different lengths and (2) large scale landslide model with locked section. The relationship of AE event count and record time was analyzed during the tests. The AE source location technology and comparative analysis with its actual failure model were done. It can be found that whether it is small scale test or large scale landslide model test, AE technique accurately located the AE source point, which reflected the failure generation and expansion of internal cracks in rock samples. Large scale landslide model with locked section test showed that rock bridge in rocky slope has typical brittle failure behavior. The two tests based on AE technique well revealed the rock failure mechanism in rocky slope and clarified the cause of high speed and long distance sliding of rocky slope.

\section{Introduction}

Acoustic emission (AE) is a phenomenon about the development of transient elastic waves caused by rapid energy release due to crack growth [1]. Early AE technique has been applied in security problems of metal mines, coal mines, and tunnel engineering. With advanced computerized technique, small sized digital $\mathrm{AE}$ analysis equipment can be used to detect the defects and its location and failure propagation. Compared with microseism [2] and other in situ detection methods $[3,4], \mathrm{AE}$ technique can forecast brittle failure before the structural failure.

Rocky landslides contain a lot of rock bridges, and researches on rock bridge were carried out by experimental methods and simulated by analytical and numerical simulation techniques. The laboratory study of $\mathrm{AE}$ characteristics during rock stress-strain process was reviewed [5]; realtime failure process $[6,7]$ and stability evaluation and harm degree of landslides [8] were marked out. Behavior of rock bridge was observed firstly by shear test in 1990 [9]; then cyclic loading test of rock bridge and mechanical behavior was carried out [10]. The failure mechanisms and pattern of coalescence of rock bridges were investigated [11]. Strength, deformability, failure behavior, and AE locations of red sandstone were tested by using triaxial compression [12]. The abovementioned tests showed the basic mechanical behavior, but the brittle failure of rock bridge was rarely tested. Analytical methods such as neural network [13], slice element method [14], and time-dependent degradation failure $[15,16]$ are used to study the progressive failure of rock bridge. Rock fragmentation processes subjected to static and dynamic loading were examined by the numerical code RFPA [17]. The progressive rock fracture mechanism of cracked chevron notched Brazilian disc rock specimens was numerically simulated [18]. Surface crack initiation and propagation were numerically investigated via parallel finite element analysis [19]. These numerical studies really revealed the progressive failure of rock bridge.

However, the brittle failure of the rock bridge, especially in the rocky slope, is rarely studied. Small scale rock bridge direct shear test and large scale landslide model test with locked section were designed in this paper. The relation curve of $\mathrm{AE}$ event count with time and $\mathrm{AE}$ source location are obtained through the AE source location technology. The 


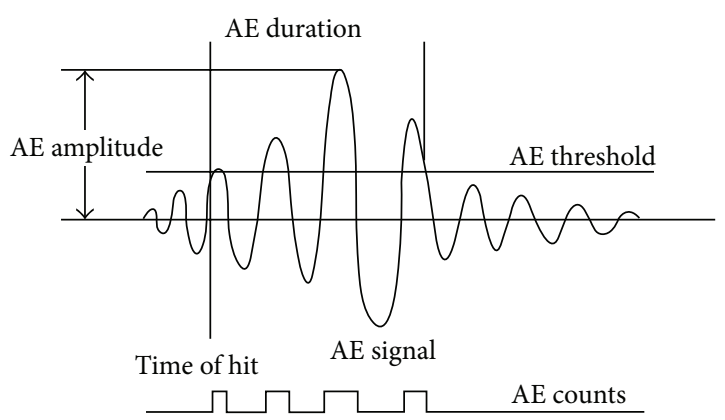

FIGURE 1: Wave hit feature of AE.

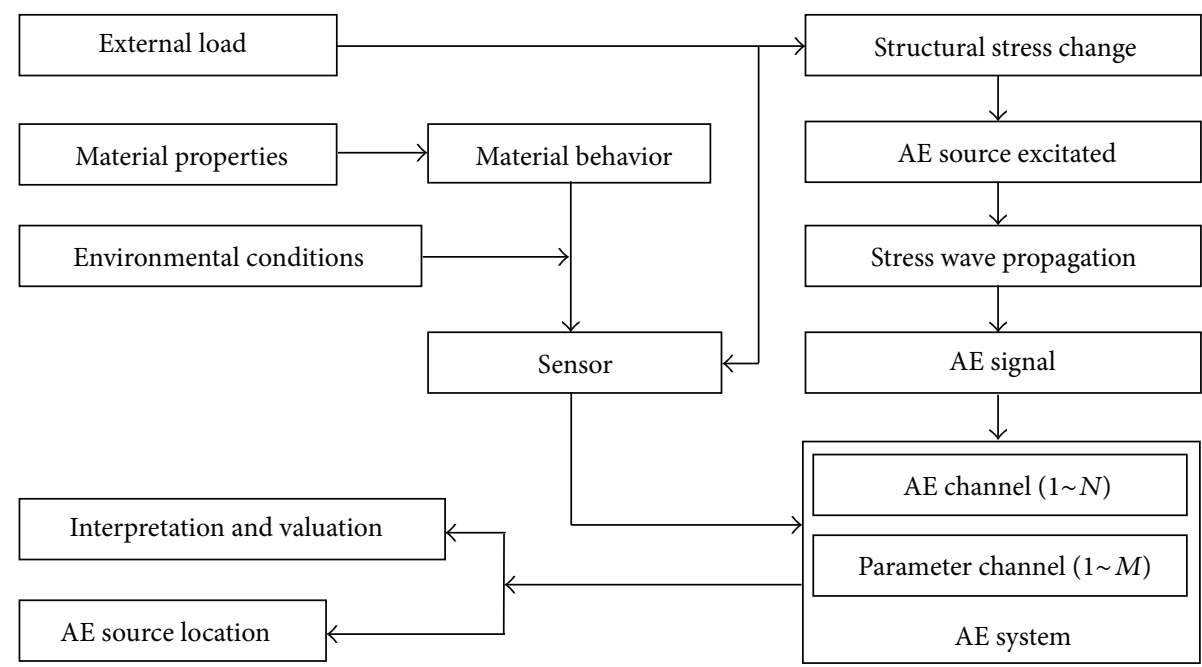

FIgURE 2: Flow chart of AE source location.

mechanical characteristics and failure mechanism of rock mass with rock bridge and the space evolution process of cracks are discussed.

\section{AE Technique}

2.1. AE Instrument and Its Principle. AE instrument is MicroII Digital AE System, which is equipped with the third generation of digital system developed by USA Physical Acoustics Company. Its core is an AE function card with 8 channels on a plate. Compared to other AE devices, Micro-II Digital AE System is one of the latest and highest integration AE systems currently which has the advantages of small volume, convenient carrying, high precision, high speed of data transmission, strong processing ability, and so on. The data obtained from Micro-II Digital AE System is more reliable and $\mathrm{AE}$ source location is more precise than other $\mathrm{AE}$ devices. Its maximum signal amplitude reached $100 \mathrm{~dB}$ and its bandwidth is $1 \sim 400 \mathrm{kHz}$.

Peripheral equipment mainly includes 2/4/6 type preamplifier with its signal gain ranging from $20 \mathrm{~dB}, 40 \mathrm{~dB}$, or $60 \mathrm{~dB}$ (adjustable), which has a high pass filtering function of $20 \mathrm{~Hz}$. Nano-30 type sensors, whose frequency response range is $100 \sim 400 \mathrm{kHz}$ and test set monitoring threshold value is $40 \mathrm{~dB}$, use six sensors array data acquisition to ensure the location precision.

AE principle is that elastic wave from $\mathrm{AE}$ source which finally transmits to the material surface causing surface displacement, which can be detected by AE sensors. These sensors convert mechanical vibration into electrical signals. Finally, according to the analysis of the obtained data, the following goals can be achieved: (1) determining the $\mathrm{AE}$ source location; (2) determining time or load of the $\mathrm{AE}$ occurrence; and (3) assessing the degrees of damage to the AE source.

Figure 1 shows AE signal waveform and partial of $\mathrm{AE}$ parameters, including $\mathrm{AE}$ count, $\mathrm{AE}$ amplitude, rise time, $\mathrm{AE}$ duration, and AE threshold. In addition, the commonly used AE characterization parameters also include energy, impact, events, energy, time difference, and frequency [20].

2.2. AE Location Technology. AE source location process is shown in Figure 2; different methods of AE source location are adapted for burst and continuous AE signals [21]. Source location of burst AE signal includes time of arrive (TOA) location and region location. Continuous AE signal location includes amplitude measurement type regional location, attenuation measurement type location, cross correlation TOA location, and interference TOA location. 
TOA location is widely used for detecting the samples and components, but it would easily lose a large number of low amplitude signals and its location accuracy may be affected by wave speed, attenuation, wave shape, and the shape of component. When the ratio of the length to the radius of the tested object becomes very large, it is appropriate by using linear location for AE detection, such as pipes, bars, and steel beam. Linear location requires at least two AE sensors. Plane location of plate structure needs at least three sensors. Threedimensional location requires at least four sensors.

The position of sound source can be calculated by the above equation. The basic principle of plane location and three-dimensional location is similar to the linear location, which are all positioned by the velocity and time difference. In this paper, the main $\mathrm{AE}$ source location is Geiger method [22] which uses the difference arrive time of $P$ wave [23].

The Geiger method is an application of the Gauss-Newton minimum fitting function; the principle is using iteration method to get the final result from a given initial point (test point). A correction vector $\Delta \theta(\Delta x, \Delta y, \Delta z, \Delta t)$ is calculated through every iteration based on the least square method; the vector $\Delta \theta$ is added to the previous iteration results (test point) to get a new test point. Then it is determined whether the new test point meets the requirements. If it does, the point is the sought source point, if not, the iteration continues until the requirement is met. The result of each iteration is produced by the following time distance equation:

$$
\left[\left(x_{i}-x\right)^{2}+\left(y_{i}-y\right)^{2}+\left(z_{i}-z\right)^{2}\right]^{1 / 2}=v_{p}\left(t_{i}-t\right),
$$

where $x, y, z$ is the test point coordinate (initial value is artificially settled), $t$ is the time of occurrence of events (initial value is artificially settled), $x_{i}, y_{i}, z_{i}$ is the sensor $i$ location, $t_{i}$ is the arrival time of $\mathrm{P}$ wave which is detected by the sensor $i$, and $v_{p}$ is the $\mathrm{P}$ wave velocity.

$t_{o i}$ is the time of $\mathrm{P}$ wave arrival of each sensor, which can be calculated by the First Order Taylor Series Expansion of arrival time through the test point coordinate:

$$
t_{o i}=t_{c i}+\frac{\partial t_{i}}{\partial x} \Delta x+\frac{\partial t_{i}}{\partial y} \Delta y+\frac{\partial t_{i}}{\partial z} \Delta z+\frac{\partial t_{i}}{\partial t} \Delta t
$$

where $t_{o i}$ is the arrival time of $\mathrm{P}$ wave detected by the sensor $i$ and $t_{c i}$ is the arrival time of sensor $i$ of $\mathrm{P}$ wave calculated by test point coordinates.

In (2),

$$
\begin{aligned}
& \frac{\partial t_{i}}{\partial x}=\frac{\left(x_{i}-x\right)}{v R}, \quad \frac{\partial t_{i}}{\partial y}=\frac{\left(y_{i}-y\right)}{v R}, \quad \frac{\partial t_{i}}{\partial z}=\frac{\left(z_{i}-z\right)}{v R}, \\
& \frac{\partial t_{i}}{\partial t}=1, \quad R=\left[\left(x_{i}-x\right)^{2}+\left(y_{i}-y\right)^{2}+\left(z_{i}-z\right)^{2}\right]^{1 / 2}
\end{aligned}
$$

For $N$ positive sensors, you can get $N$ equations written in matrix form:

$$
A \Delta \theta=B
$$

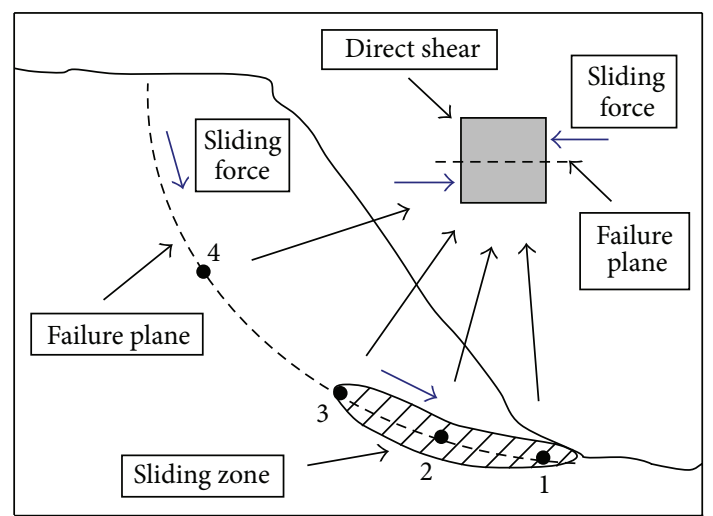

FIGURE 3: Sketch map of rock slope failure.

where

$$
A=\left[\begin{array}{cccc}
\frac{\partial t_{1}}{\partial x} & \frac{\partial t_{1}}{\partial y} & \frac{\partial t_{1}}{\partial z} & 1 \\
\frac{\partial t_{2}}{\partial x} & \frac{\partial t_{2}}{\partial y} & \frac{\partial t_{2}}{\partial z} & 1 \\
\vdots & \vdots & \vdots & \vdots \\
\frac{\partial t_{n}}{\partial x} & \frac{\partial t_{n}}{\partial y} & \frac{\partial t_{n}}{\partial y} & 1
\end{array}\right], \quad B=\left[\begin{array}{c}
t_{o 1}-t_{c 1} \\
t_{o 2}-t_{c 2} \\
\vdots \\
t_{o n}-t_{c n}
\end{array}\right] .
$$

Modification vector is got by Gaussian Elimination (4):

$$
\begin{gathered}
A^{T} A \Delta \theta=A^{T} B, \\
\Delta \theta=\left(A^{T} A\right)^{-1} A^{T} B .
\end{gathered}
$$

After correction vector is obtained by (7), use $(\theta+\Delta \theta)$ as the new test point to keep iteration continuous until the error satisfies the requirements.

\section{Small Scale Direct Shear Tests with Different Rock Bridge Length}

Many scholars have studied macrofailure and micropropagation of cracks evolution under shear loading, such as simulating microdevelopment of crack using cellular automata $[24,25]$, time distribution features of rock crack [26], brittle failure mechanism of rock [27], the influence of size effect on rock failure [28], and differential resistance sensing technology [29]. But small scale direct shear tests of different rock bridge length using $\mathrm{AE}$ are few.

As shown in Figure 3, the points on the failure plane are directly sheared to failure in sliding process. From a microscopic view point, the failure process of rock bridge of landslide is the direct shear failure. So rock bridge direct shear tests are carried out in order to study the failure mechanism with different rock bridge length in this paper.

3.1. Sample Preparation and Test Instrument. The mass ratio of test sample is 1:3:1:1 (cement:sand:water:gypsum). 

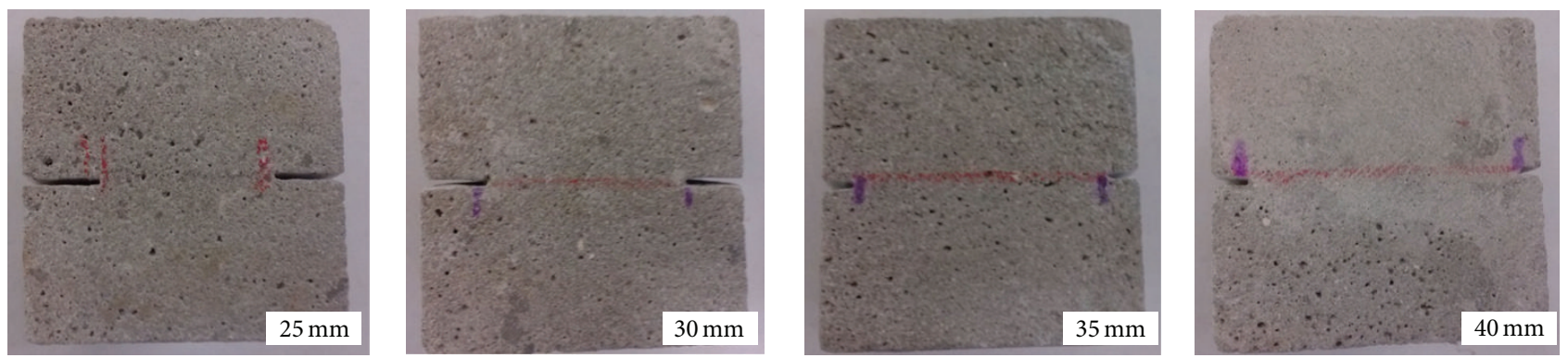

FIGURE 4: Different reserved rock bridge length.

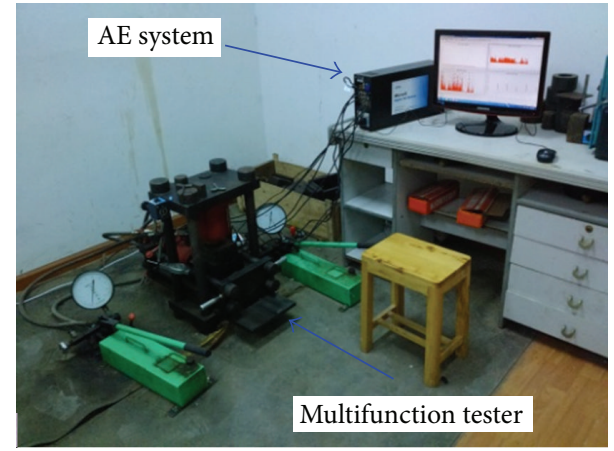

FIGURE 5: Direct shear test system associate with AE system.

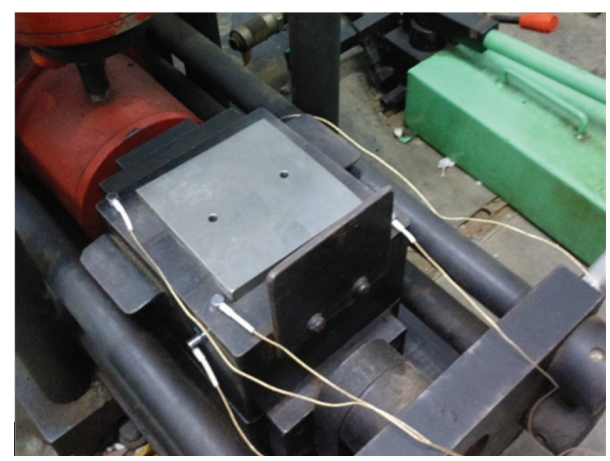

Figure 6: AE sensor arrangement.

According to the requirements of test instrument, the samples were processed into $50 * 50 * 50 \mathrm{~mm}^{3}$. The samples were divided into 4 groups and each sample is $25 \mathrm{~mm}, 30 \mathrm{~mm}$, $35 \mathrm{~mm}$, and $40 \mathrm{~mm}$, respectively (Figure 4 ).

The tests make use of two sets of devices that would load control system and AE monitoring system (Figure 5). The test instrument can be used to reasonably simulate rock stress condition, obtain the accurate parameters of shear strength, and complete stress-strain curve of sample. AE monitoring system is Micro-II Digital AE System which can be used to conduct real-time monitoring and record the whole process of the test. AE sensor arrangement is shown in Figure 6.

3.2. Test Method. The tests were divided in four groups of 16 samples. The sample was loaded in sample box, while AE sensor was attached to the surface of sample box by means of coupling agent. Ready after all, the sample was applied positive pressure by means of normal jack and pressure values of each set of 4 samples under the vertical pressure were $0.4 \mathrm{MPa}, 0.6 \mathrm{MPa}, 0.8 \mathrm{MPa}$, and $1.0 \mathrm{MPa}$, respectively. Positive pressure was applied after completion and then shear stress was applied by using the horizontal jack. AE monitoring system came to work at the same time. Horizontal pressure was applied until the sample failure and pressure gauge data were recorded in order to obtain horizontal shearing forces during the test. AE monitoring system records the $\mathrm{AE}$ activity of rock automatically.

\subsection{Test Results and Analysis}

3.3.1. The Characteristics of AE Event Counts. To explore the $\mathrm{AE}$ change pattern under different rock bridge length and different vertical pressure, the $\mathrm{AE}$ event count with time graph is obtained under different rock bridge lengths of sample including $25 \mathrm{~mm}, 30 \mathrm{~mm}, 35 \mathrm{~mm}$, and $40 \mathrm{~mm}$ under $0.6 \mathrm{MPa}$ vertical pressures (Figure 7), and the $\mathrm{AE}$ event count is obtained when vertical pressure of sample is $0.4 \mathrm{MPa}, 0.6 \mathrm{MPa}, 0.8 \mathrm{MPa}$, and $1.0 \mathrm{MPa}$ with $30 \mathrm{~mm}$ rock bridge length (Figure 8 ). The AE event peak count with the rock bridge length and the vertical pressure graph are also mapped (Figures 9 and 10).

It can be seen that the sample failure mechanism has the following characteristics.

(1) In Figures 7 and 9, AE activity is more frequent and the appearance time of the $\mathrm{AE}$ event count peak value also increases with the increase of rock bridge length. This is because the arrival time of peak value increases with shear area under the same conditions, while shear area gains with rock bridge length.

(2) In Figures 8 and 10, AE event counts with the time have the same change trend; AE activity is more frequent. With the increasing of vertical pressure, $\mathrm{AE}$ event count peak value occurs much later. Shear stress increases with normal stress based on MohrCoulomb yield criterion, so the appearance time of peak value delays with the increase in vertical pressure. 


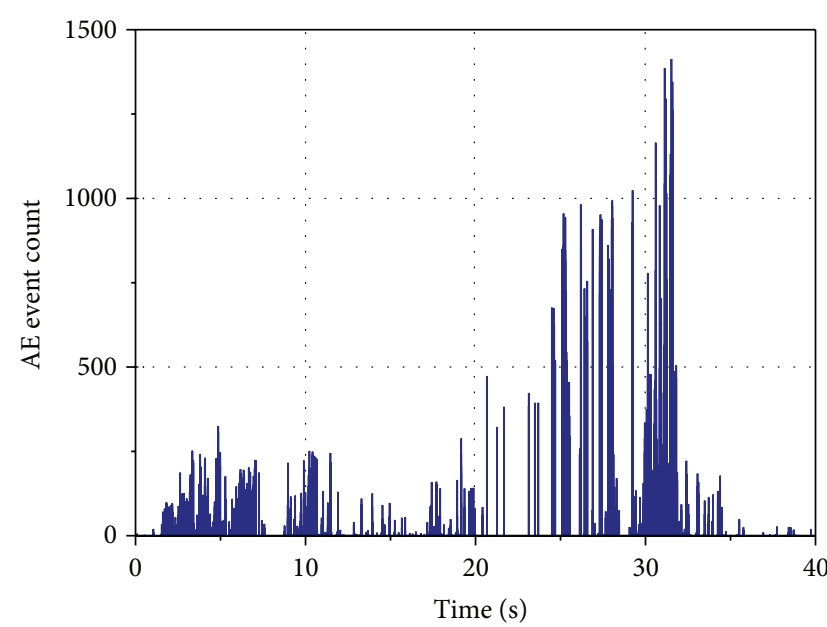

(a) Rock bridge length is $25 \mathrm{~mm}$

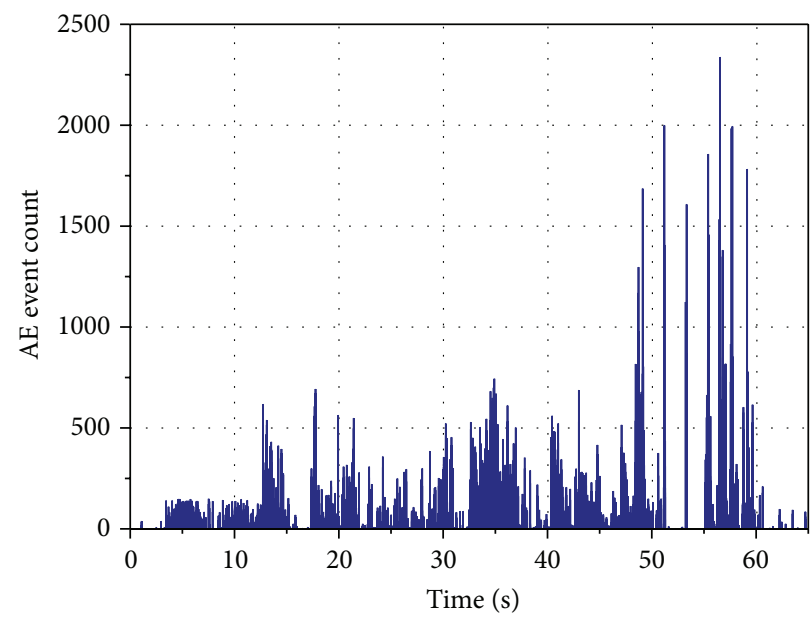

(c) Rock bridge length is $35 \mathrm{~mm}$

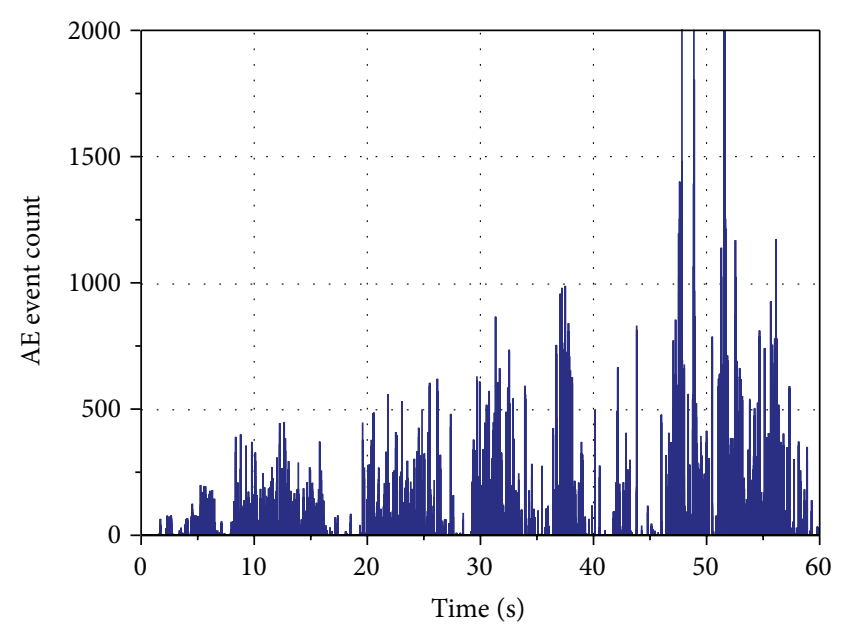

(b) Rock bridge length is $30 \mathrm{~mm}$

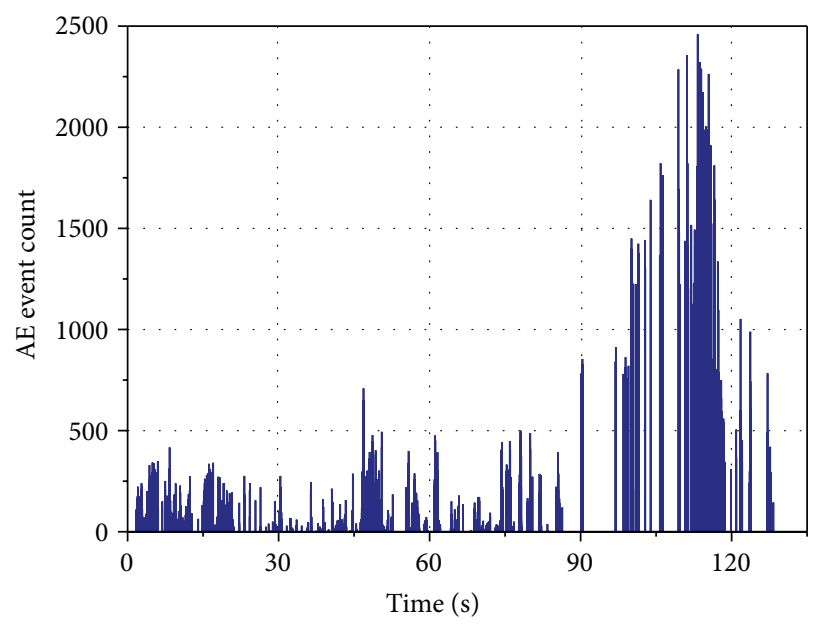

(d) Rock bridge length is $40 \mathrm{~mm}$

Figure 7: Relationship of AE event count and time at $0.6 \mathrm{MPa}$ normal pressure under different rock bridge lengths.

\subsubsection{Characteristics of AE Three-Dimensional Location.} Figure 11 is the AE source location and the actual failure under different rock bridge lengths of $25 \mathrm{~mm}, 30 \mathrm{~mm}, 35 \mathrm{~mm}$, and $40 \mathrm{~mm}$ under $0.6 \mathrm{MPa}$ vertical pressure. Figure 12 is the $\mathrm{AE}$ source location of samples and the actual failure under different vertical pressure, consisting of $0.4 \mathrm{MPa}$, $0.6 \mathrm{MPa}, 0.8 \mathrm{MPa}$, and $1.0 \mathrm{MPa}$ under $30 \mathrm{~mm}$ length. Threedimensional location result is shown by a side of sample in a picture to make $\mathrm{AE}$ three-dimensional location patterns more clear, and also it leads to some location points which overlap with each other. It can be found that the AE source location and the macroscopic failure mode of rock are in good match in Figures 11 and 12. The AE source location also has the following characteristics.

(1) In Figure 11, the number of AE location points was obtained with the increase of the rock bridge length. The crack shear angle increases from the horizontal direction to a certain angle, and the number of microcracks increases in the same vertical pressure under the different rock bridge length. It seems that location points with rock bridge of $30 \mathrm{~mm}$ break less than those with $25 \mathrm{~mm}$ in Figure 11.

(2) In Figure 12, the number of $\mathrm{AE}$ location points increases and its distribution is comparatively dispersive with the increase of vertical pressure; the crack shear angle was obtained from the horizontal direction to a certain angle in different vertical pressure under the same rock bridge length. The sample is easier to break with the increase of vertical pressure.

3.3.3. Failure Mechanism and Characteristics of Samples. As shown in Figure 13, it can be found that failure process can be divided into three stages by strain value.

(1) Stage 1 is the stage where strain value is $1 \sim 2 \%$ in which the shear stress is less than the shear strength of rock. The shear stress is much higher at the tip of rock bridge and the distribution of stress on the shear surface is uniform. At this stage, the AE activity is less, and it remains at a lower level and increases slowly. 


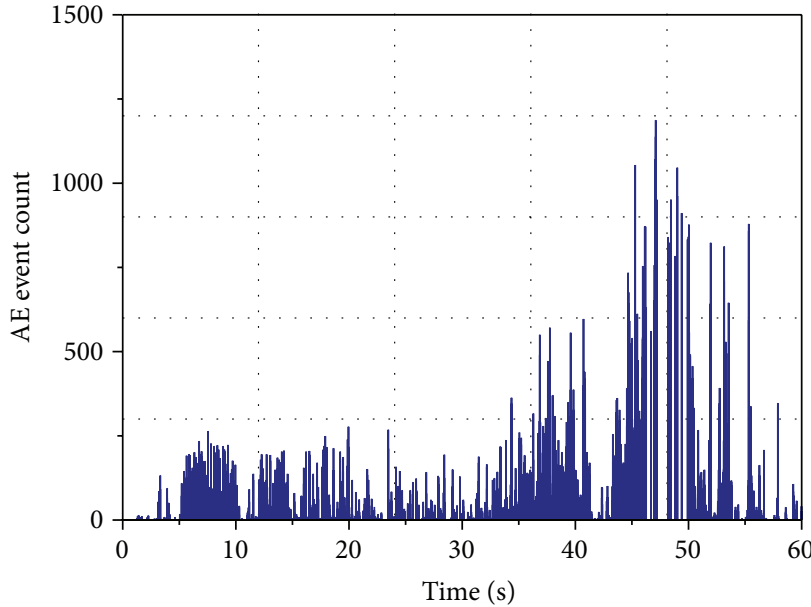

(a) The pressure is $0.4 \mathrm{MPa}$

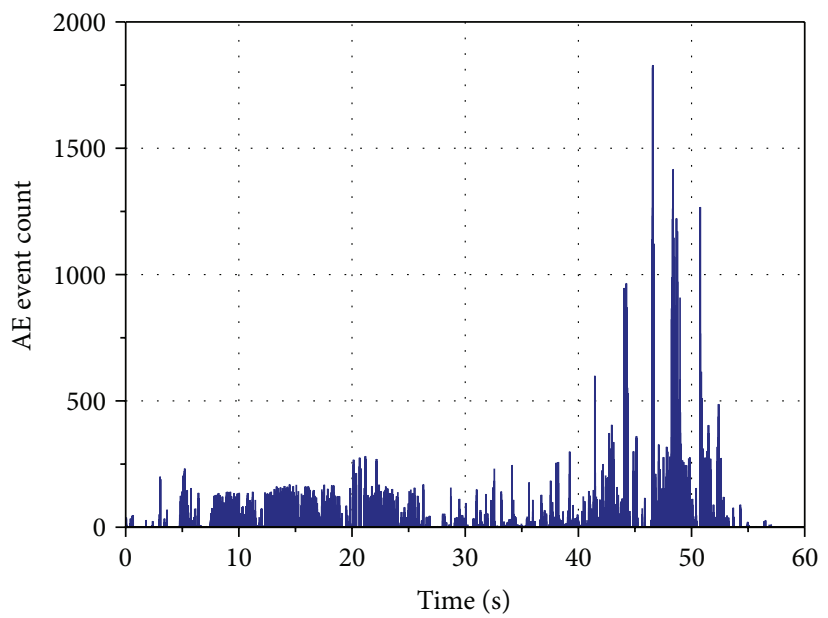

(c) The pressure is $0.8 \mathrm{MPa}$

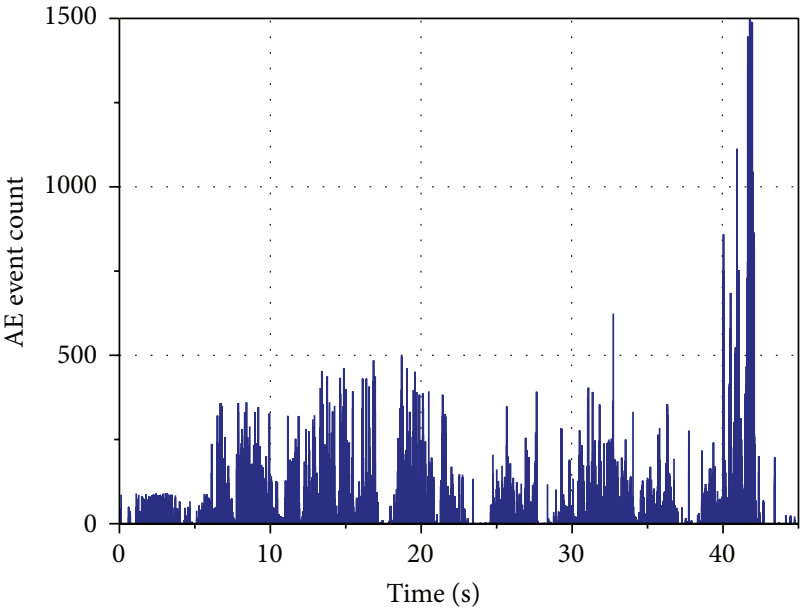

(b) The pressure is $0.6 \mathrm{MPa}$

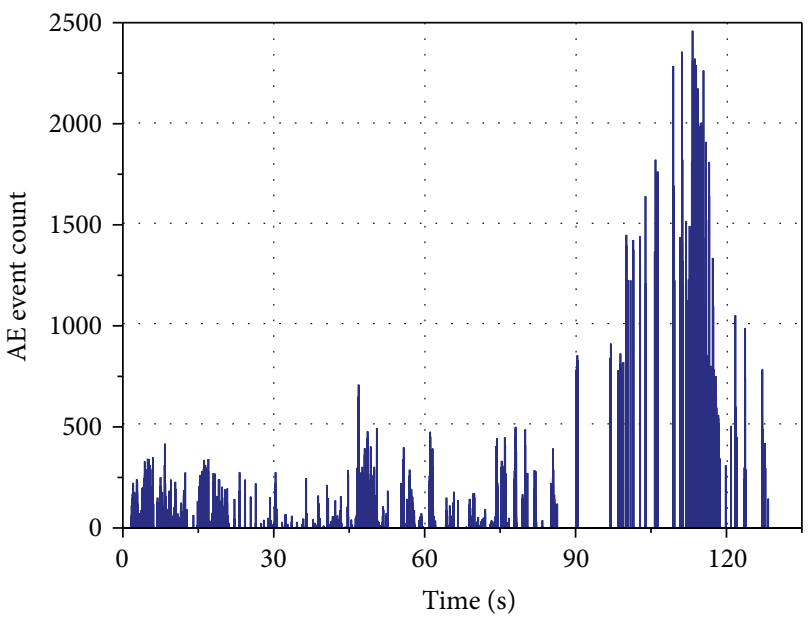

(d) The pressure is $1.0 \mathrm{MPa}$

FIGURE 8: Relationship of AE event count and time at $30 \mathrm{~mm}$ rock bridge length under different vertical pressure.

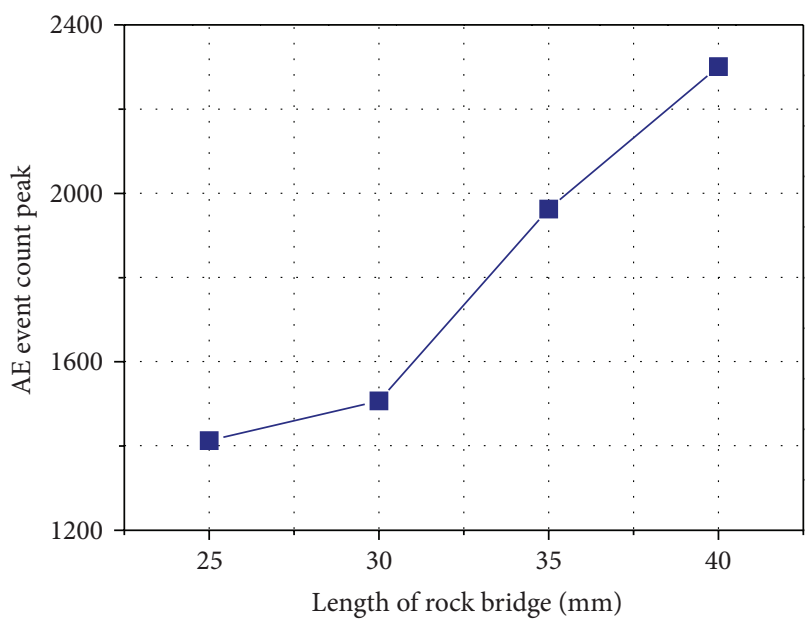

Figure 9: Relationship curves between AE event count peak and rock bridge length.

(2) Stage 2 is the stage where strain value is $2 \sim 3 \%$; the sample enters the stage of plastic deformation and

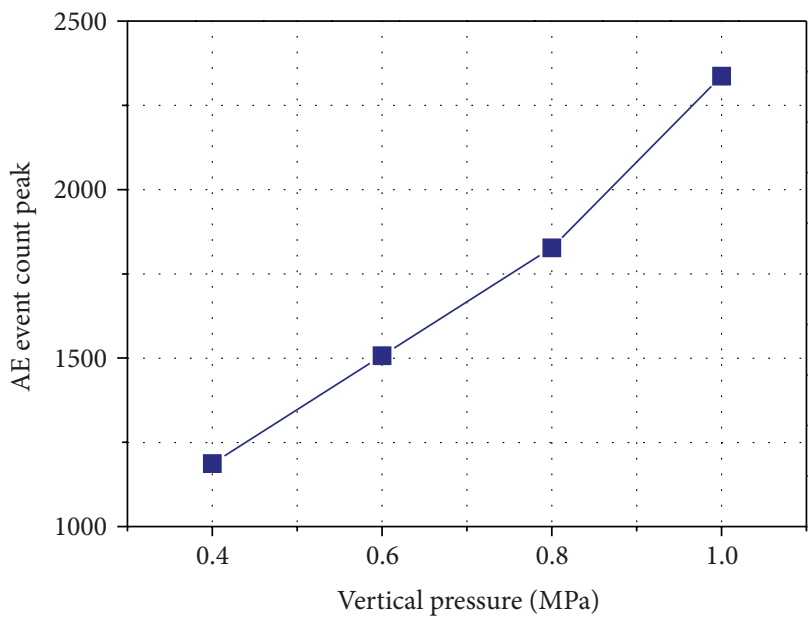

FIgURE 10: Relationship curves between AE event count peak and vertical pressure.

begins to develop cracks with the increase of shear stress. Because of the stress concentration at the tip 

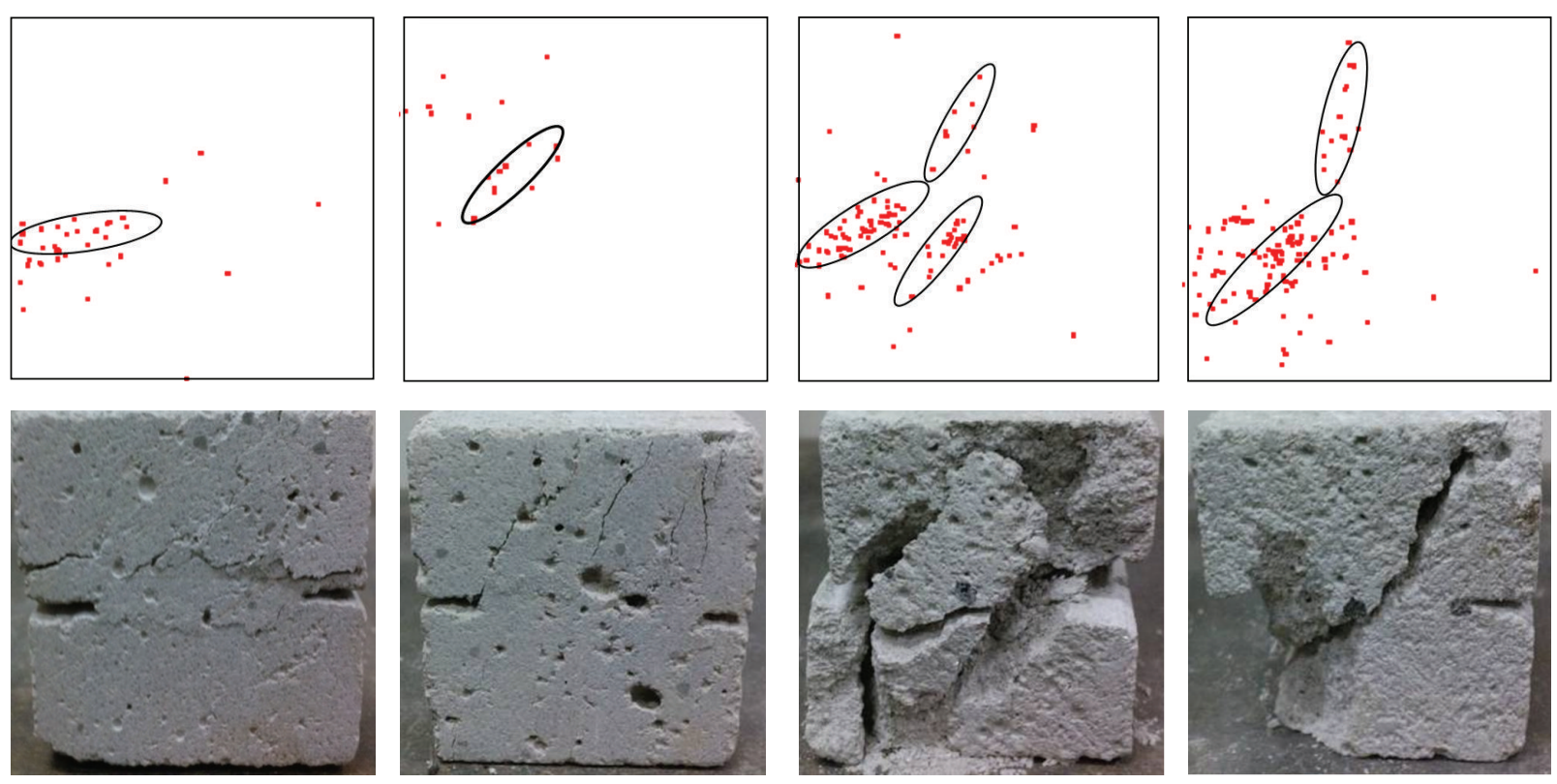

FIGURE 11: AE source locations of sample and the actual failure under different rock bridge length (25 mm, $30 \mathrm{~mm}, 35 \mathrm{~mm}$, and $40 \mathrm{~mm})$.
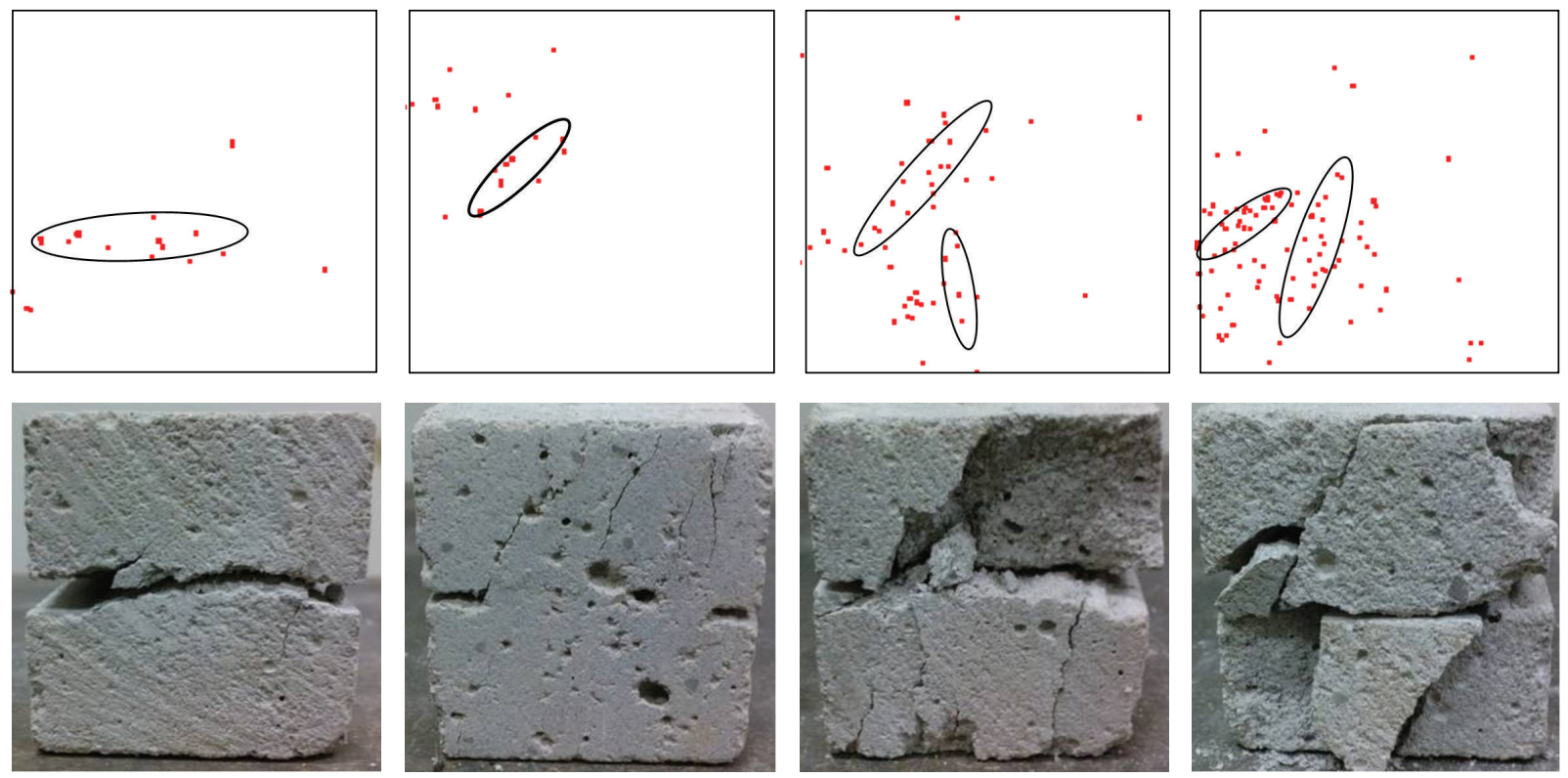

FIGURE 12: AE source locations of sample and the actual failure under different vertical pressure (0.4 MPa, 0.6 MPa, $0.8 \mathrm{MPa}$, and $1.0 \mathrm{MPa})$.

of rock bridge, the cracks often generate firstly from the tip of the rock bridge and finally grow into the main crack, and there form several groups of larger cracks parallel to the main crack near the rock bridge. A sudden integral brittle fracture occurs along the main rupture surface of the sample when the shear stress reaches the shear strength of rock. At this stage, $\mathrm{AE}$ activity frequency increases rapidly and AE count peak appears when the sample shear stress reaches the maximum value.

(3) Stage 3 is the stage with strain value after reaching $3 \%$. As the sample is further damaged, the shear stress decreases rapidly and cracks extend further. At the end, the sample is completely cut out. At this stage, AE activity decays rapidly after maximum shear stress value and this stage is often shorter than others.

\section{Large Scale Landslide Model with Locked Section Test}

The locked section of rock slope refers to rock bridge near middle of sliding zone which has a relatively highly strength. The occurrence of large-scale rock landslides is generally accompanied by sudden brittle failure of the "locked 


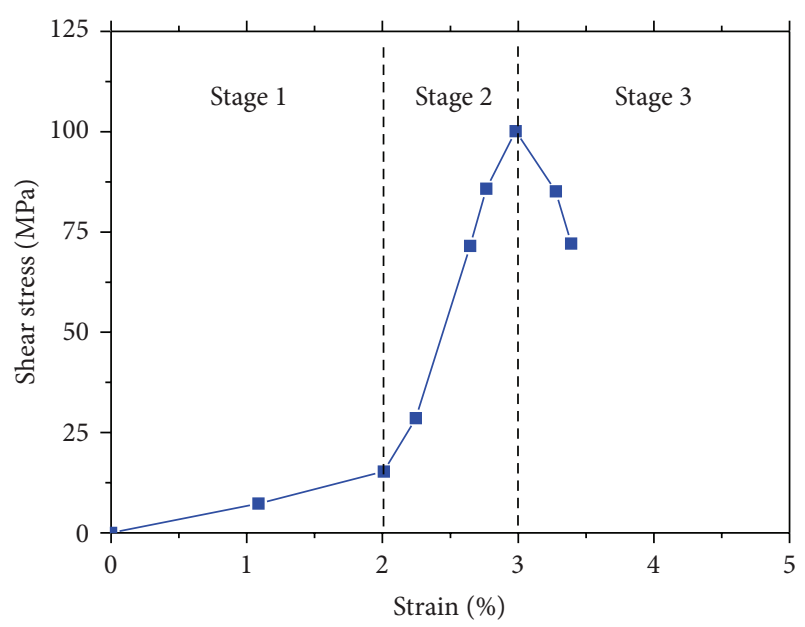

FIGURE 13: Sample stress-strain curve of direct shear test.

section." It means that "locked section" plays an important role in deformation control and stability mechanism of rock slope, hence a key in assessment and control on slope disaster.

Some authors had investigated the micro- and macrocharacteristics of shear or tensile failure under the action of gravity creep by the view of creep mechanics of rock mass [30]. Some authors had researched the creep fracture degree of bedrock and distribution of serious landslide hazard areas by using seismic wave velocity test [31] and other methods [32]. The researches were carried out to study locked section in various aspects, but the AE technique is rarely used. In this paper, the dynamic test characteristics of AE are used to carry out the large scale landslide model test with locked section to have a further study on its failure mechanism.

4.1. Samples Preparation and Test Instruments. The mass ratio of test sample is set at 1:3:1:1 (cement:sand:water:gypsum), with the sample size shown in Figure 14(a). The locked section is circular arc and reserved length of $65 \mathrm{~mm}$. The test system uses a multisystem integrated test method in order to achieve a better physical simulation condition. Loading platform is two-dimension geological system framework and it is $4 \mathrm{~m}$ long, upper beam $2.5 \mathrm{~m}$ high, and foot beam $0.3 \mathrm{~m}$ high. Hydraulic jack which contacts the model is fixed on the framework and controlled by hydraulic system. The jack provides different pressure to simulate the sliding of gravity according to the test requirement. The arrangement of $\mathrm{AE}$ sensors is shown in Figure 14(b). The bedrock boundary is fixed with the sliding mass boundary being set free. Vertical load is imposed on upper part of sliding mass.

4.2. Test Method. After the installing of AE system and sensors, then starting the hydraulic control system, controlling oil pump to create pressure, and taking gradual loading increase by $2 \mathrm{MPa}$ every level, the gradual loading changes to $1 \mathrm{MPa}$ every level when the crack propagation is obvious in locked section until the model failure during the end loading phase. The AE keep monitoring and recording during the whole test process.

\subsection{Test Results and Analysis}

4.3.1. The Characteristics of AE Event Count and AE Energy. According to test data, the AE event count and AE energy change with time during test progress of landslide model with the locked section are shown in Figure 15. The following can be concluded from Figure 15.

It can be seen from Figure 15 that the test is not like the direct shear test. The energy of locked section accumulates continuously because of the increase of stress. The energy suddenly releases and then rock mass of locked section is cut out. This process has the characteristic of sudden and brittle failure; it reflects the development process of rock slope that from the progressive damage evolutes to brittle failure. AE event count with time and AE energy with time of slope model with locked section are almost the same as each other where both have the same change trend and characteristics. It can be corroborated to well respond to the deformation and failure characteristics of the slope model.

4.3.2. Characteristics of AE Plane Location. The failure process and characteristics of locked section test model are examined through the comparison of Figure 16; the conclusion is as follows.

(1) In Figure 16, the failure surface is basically in the predetermined locked section; along with locked section, an inclined plane is formed with the right being high and the left being low. The length of shear failure section is about $40 \mathrm{~mm}$, and the shear failure surface has obvious scratches. The tensile failure section is $20 \mathrm{~mm}$, and tension cracks can be observed obviously (Figure 16(a)).

(2) It can be found in Figure 16(b) that the AE source location is in accordance with the actual failure. Analysis of AE source location process shows that the location point first appears in the outside of sensor array, and its position finally locates within the twosensor array as AE source points appear continuously with the time. The location point is more intensive at the edge of locked section because of the stress concentration.

(3) From the perspective of overall effect of AE source and its location technology, AE source located accurately and the space-time evolution of cracks in locked section is reflected; the failure process and characteristics of slope during the localization process can also be demonstrated. Rock landslide with locked section has the characteristics such as higher energy accumulation, the sudden release of energy, and brittle failure, which cause long sliding distance and serious failure. 


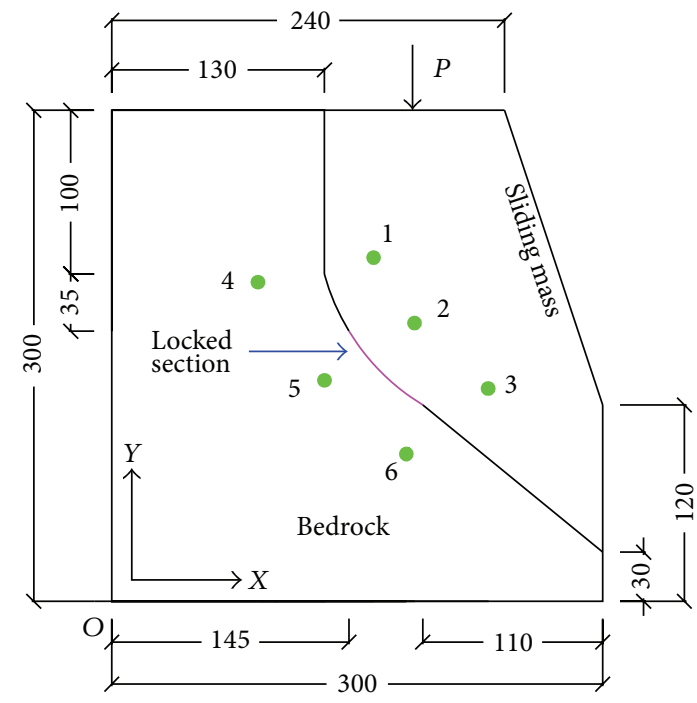

(a) Schematic diagram $(\mathrm{mm})$

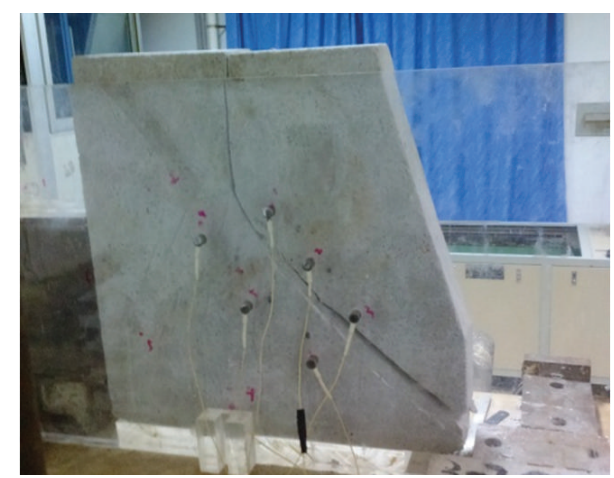

(b) Actual sample

FIGURE 14: Sample size and sensor position.

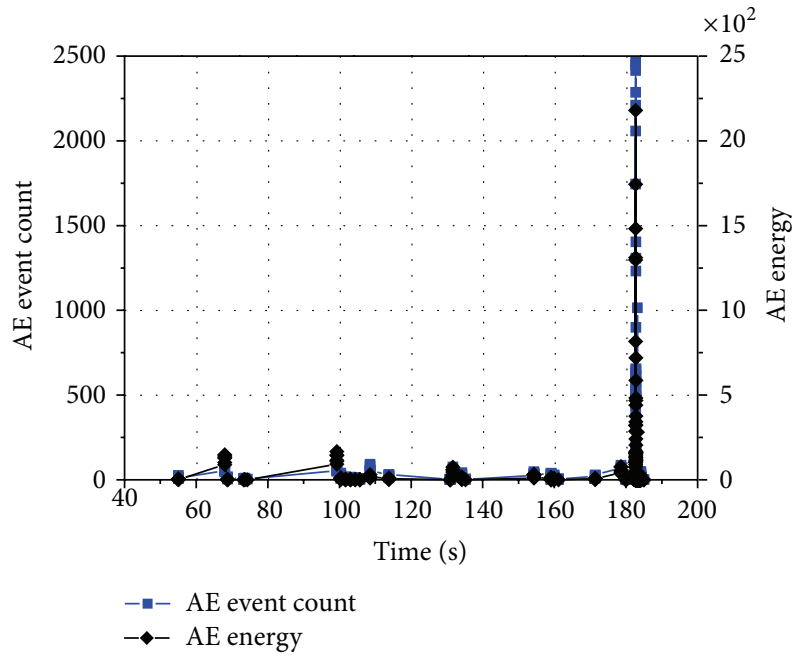

FIGURE 15: Relationship curves of AE event count with time and AE energy with time.

\section{Conclusion}

In this paper, small scale direct shear tests with different lengths and large scale rock landslide model with locked section test are carried out; both of them aim to study the failure mechanism and mechanics characteristics of rock bridge of landslide. The $\mathrm{AE}$ event count and $\mathrm{AE}$ source location under different circumstances are analyzed. The conclusions can be summarized as follows.

(1) AE source location can be accurately located during small scale tests in small scale direct shear tests. the $\mathrm{AE}$ event count peak value increases with the increasing of rock bridge length and vertical stress.
In addition, the time of $\mathrm{AE}$ event count peak value appearing goes back with the increase of the length and the vertical stress.

(2) AE resource location was accurately and reliably located during large scale landslide model test with locked section. Based on the locating process, rock sample failure features and cracks time-space evolution process were revealed. AE showed that the brittle failure feature of landslide with locked section was reflected well.

(3) AE technology plays an important role in rock mechanics and related research fields. The two tests based on AE technique well revealed the rock failure mechanism in rocky slope and clarified the reason of high speed and long distance sliding of rocky slope that cause serious disasters and catastrophe.

\section{Conflict of Interests}

The authors declare that there is no conflict of interests regarding the publication of this paper.

\section{Acknowledgments}

This work is supported by the National Basic Research Program of China (973 Program, no. 2013CB733202) and the National Natural Science Foundation of China (Grant nos. 41272330 and 41130745). This work is also supported by the funding of Science and Technology Office of Sichuan Province (Grant no. 2015JQO020). 


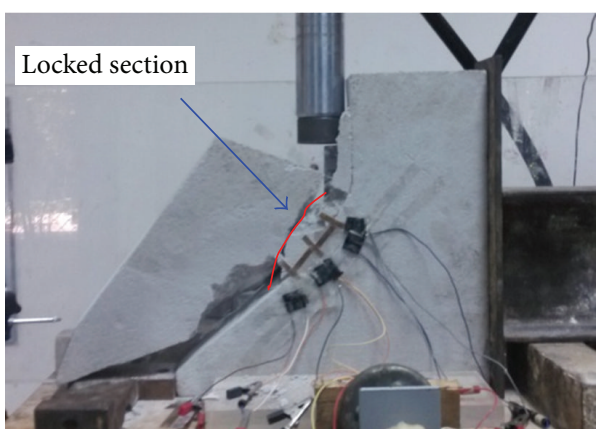

(a) Failure of locked section

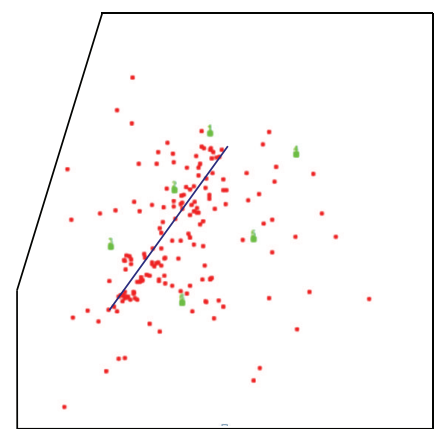

(b) AE source location of failure

FigURE 16: Failure of locked section under continuous loading.

\section{References}

[1] D. Lockner, "The role of acoustic emission in the study of rock fracture," International Journal of Rock Mechanics and Mining Sciences and, vol. 30, no. 7, pp. 883-899, 1993.

[2] N. W. Xu, C. A. Tang, L. C. Li et al., "Microseismic monitoring and stability analysis of the left bank slope in Jinping first stage hydropower station in Southwestern China," International Journal of Rock Mechanics and Mining Sciences, vol. 48, no. 6, pp. 950-963, 2011.

[3] S. Li, X.-T. Feng, Z. Li, B. Chen, C. Zhang, and H. Zhou, "In situ monitoring of rockburst nucleation and evolution in the deeply buried tunnels of Jinping II hydropower station," Engineering Geology, vol. 137-138, pp. 85-96, 2012.

[4] Q. Jiang, J. Cui, and J. Chen, “Time-dependent damage investigation of rock mass in an in situ experimental tunnel," Materials, vol. 5, no. 8, pp. 1389-1403, 2012.

[5] V. Rudajev, J. Vilhelm, and T. Lokajíček, "Laboratory studies of acoustic emission prior to uniaxial compressive rock failure," International Journal of Rock Mechanics and Mining Sciences, vol. 37, no. 4, pp. 699-704, 2000.

[6] D. P. Jansen, S. R. Carlson, R. P. Young, and D. A. Hutchins, "Ultrasonic imaging and acoustic emission monitoring of thermally induced microcracks in Lac du Bonnet granite," Journal of Geophysical Research, vol. 98, no. 12, pp. 22231-22243, 1993.

[7] S. Wang, R. Huang, P. Ni, R. P. Gamage, and M. Zhang, "Fracture behavior of intact rock using acoustic emission: experimental observation and realistic modeling," Geotechnical Testing Journal, vol. 36, no. 6, 2013.

[8] D.-S. Cheon, Y.-B. Jung, E.-S. Park, W.-K. Song, and H.-I. Jang, "Evaluation of damage level for rock slopes using acoustic emission technique with waveguides," Engineering Geology, vol. 121, no. 1-2, pp. 75-88, 2011.

[9] C. Li, O. Stephansson, and T. Savilahti, "Behavior of rock joints and rock bridges in shear testing," in Proceedings of the International Symposium on Rock Joints, pp. 259-266, 1990.

[10] B. Shen and O. Stephansson, "Cyclic loading characteristics of joints and rock bridges in a jointed rock specimen," in Proceedings of the International Symposium on Rock Joints, pp. 725-729, 1990.

[11] R. H. C. Wong, K. T. Chau, P. M. Tsoi, and C. A. Tang, "Pattern of coalescence of rock bridge between two joints under shear testing," in Proceedings of the 9th International Congress on Rock Mechanics, pp. 735-738, 1999.
[12] S.-Q. Yang, H.-W. Jing, and S.-Y. Wang, "Experimental investigation on the strength, deformability, failure behavior and acoustic emission locations of red sandstone under triaxial compression," Rock Mechanics and Rock Engineering, vol. 45, no. 4, pp. 583-606, 2012.

[13] A. Ghazvinian, V. Sarfarazi, S. A. Moosavi et al., "Analysis of crack coalescence in rock bridges using neural network," in Proceedings of the European Rock Mechanics Symposium, pp. 255-258, 2010.

[14] F.-M. Zhang, B.-H. Wang, Z.-Y. Chen, X.-G. Wang, and Z.-X. Jia, "Rock bridge slice element method in slope stability analysis based on multi-scale geological structure mapping," Journal of Central South University of Technology, vol. 15, no. 2, pp. 131-137, 2008.

[15] J. Kemeny, "Time-dependent drift degradation due to the progressive failure of rock bridges along discontinuities," International Journal of Rock Mechanics and Mining Sciences, vol. 42, no. 1, pp. 35-46, 2005.

[16] W. Zhu, S. Li, R. H. C. Wong, K. T. Chau, and J. Xu, "A study of fracture mechanism and shear strength of rock bridges through analytical and model-testing methods," Key Engineering Materials, vol. 261-263, pp. 225-230, 2004.

[17] S. Y. Wang, W. Sloan, H. Y. Liu, and C. A. Tang, "Numerical simulation of the rock fragmentation process induced by two drill bits subjected to static and dynamic (impact) loading," Rock Mechanics and Rock Engineering, vol. 44, no. 3, pp. 317332, 2011.

[18] F. Dai, M. D. Wei, N. W. Xu, Y. Ma, and D. S. Yang, "Numerical assessment of the progressive rock fracture mechanism of cracked chevron notched Brazilian disc specimens," Rock Mechanics and Rock Engineering, 2014.

[19] Z. Z. Liang, H. Xing, S. Y. Wang, D. J. Williams, and C. A. Tang, "A three-dimensional numerical investigation of the fracture of rock specimens containing a pre-existing surface flaw," Computers and Geotechnics, vol. 45, pp. 19-33, 2012.

[20] H. G. Li, R. Zhang, M. Z. Gao, G. Wu, and Y. F. Zhang, "Advances in technology of acoustic emission of rock," Chinese Journal of Underground Space and Engineering, vol. 9, pp. 1794-1804, 2013.

[21] Y.-L. Ding, Y. Deng, and A.-Q. Li, "Advances in researches on application of acoustic emission technique to health monitoring for bridge structures," Journal of Disaster Prevention and Mitigation Engineering, vol. 30, no. 3, pp. 341-351, 2010.

[22] L. Geiger, "Probability method for the determination of earthquake epicenters from the arrival time only," Bulletin of St. Louis University, vol. 8, pp. 60-71, 1912. 
[23] W. Spence, "Relative epicenter determination using P-wave arrival-time differences," Bulletin of the Seismological Society of America, vol. 70, no. 1, pp. 171-183, 1980.

[24] P.-Z. Pan, F. Yan, and X.-T. Feng, "Modeling the cracking process of rocks from continuity to discontinuity using a cellular automaton," Computers \& Geosciences, vol. 42, pp. 87-99, 2012.

[25] X. T. Feng, P. Z. Pan, and H. Zhou, "Simulation of the rock microfracturing process under uniaxial compression using an elasto-plastic cellular automaton," International Journal of Rock Mechanics and Mining Sciences, vol. 43, no. 7, pp. 1091-1108, 2006.

[26] X.-T. Feng and M. Seto, "Fractal structure of the time distribution of microfracturing in rocks," Geophysical Journal International, vol. 136, no. 1, pp. 275-285, 1999.

[27] G. Chen, T. Li, G. Zhang, H. Yin, and H. Zhang, “Temperature effect of rock burst for hard rock in deep-buried tunnel," Natural Hazards, vol. 72, no. 2, pp. 915-926, 2014.

[28] D. Y. Li, C. C. Li, and X. B. Li, "Influence of sample height-towidth ratios on failure mode for rectangular prism samples of hard rock loaded in uniaxial compression," Rock Mechanics and Rock Engineering, vol. 44, no. 3, pp. 253-267, 2011.

[29] G. Zhao, H. Pei, and H. Liang, "Measurement of additional strains in shaft lining using differential resistance sensing technology," International Journal of Distributed Sensor Networks, vol. 2013, Article ID 153834, 6 pages, 2013.

[30] M. Chigira, "Long-term gravitational deformation of rocks by mass rock creep," Engineering Geology, vol. 32, no. 3, pp. 157184, 1992.

[31] N. W. Xu, F. Dai, Z. Z. Liang, Z. Zhou, C. Sha, and C. A. Tang, "The dynamic evaluation of rock slope stability considering the effects of microseismic damage," Rock Mechanics and Rock Engineering, vol. 47, no. 2, pp. 621-642, 2014.

[32] G. S. Zhao, G. Q. Zhou, X. D. Zhao, Y. Z. Wei, and L. J. Li, "R/S analysis for stress evolution in shaft lining and fracture prediction method," Advanced Materials Research, vol. 374-377, pp. 2271-2274, 2012. 

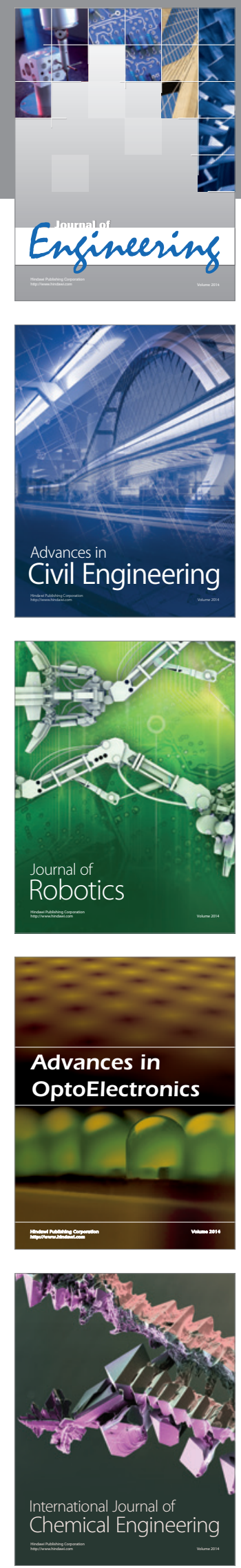

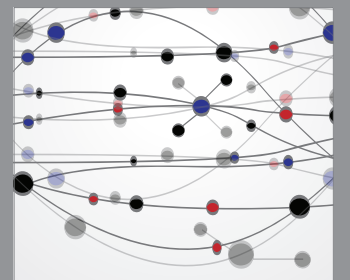

The Scientific World Journal
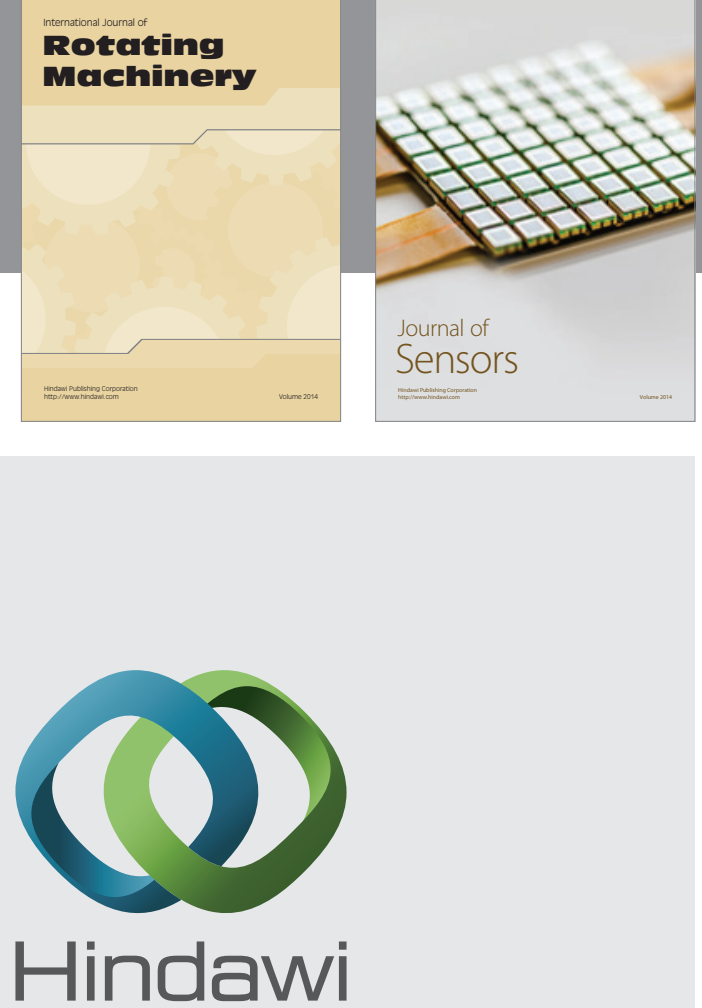

Submit your manuscripts at http://www.hindawi.com
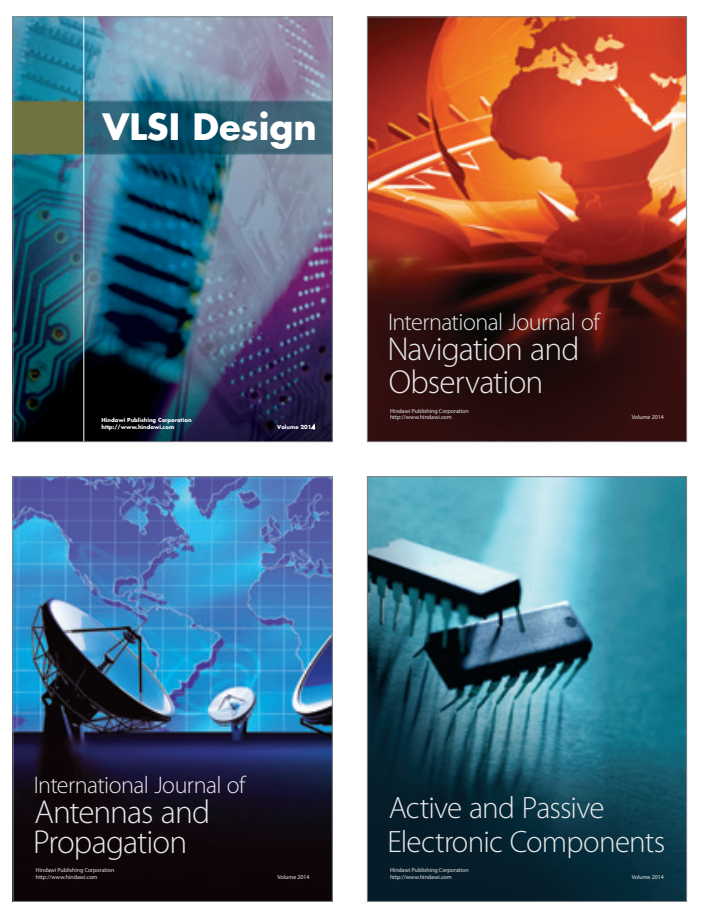
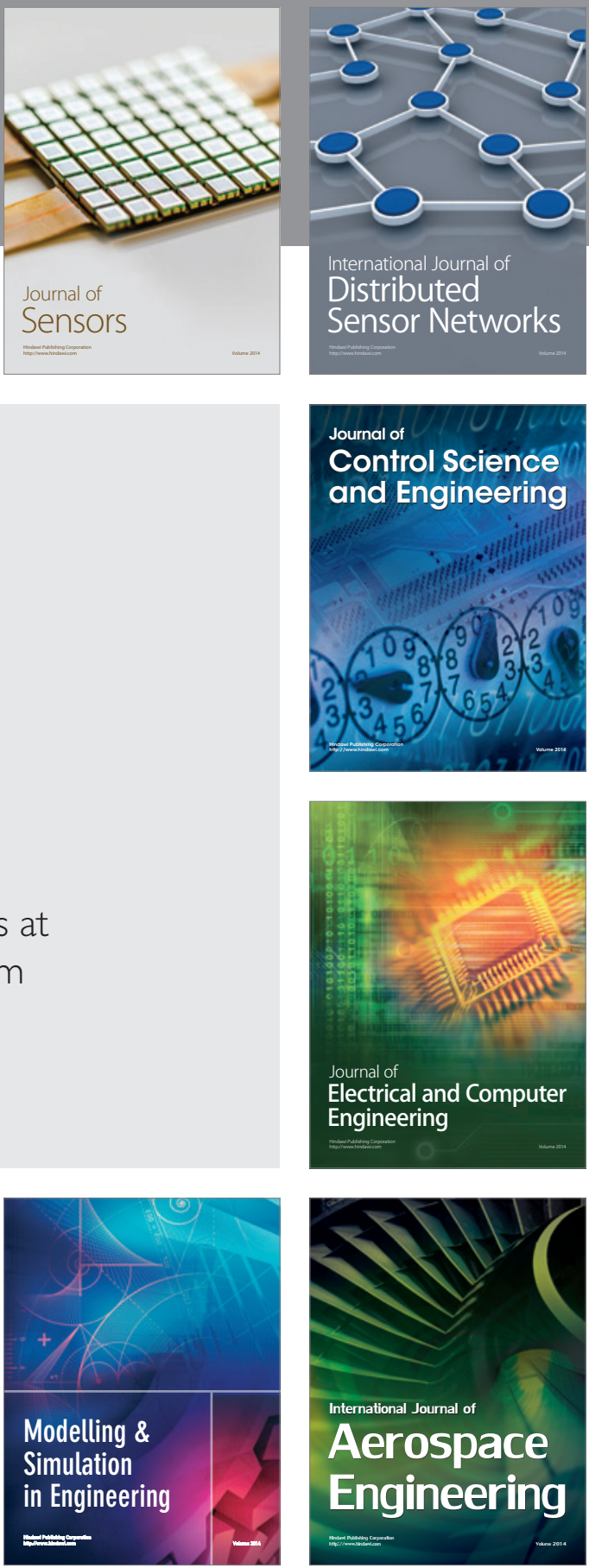

Journal of

Control Science

and Engineering
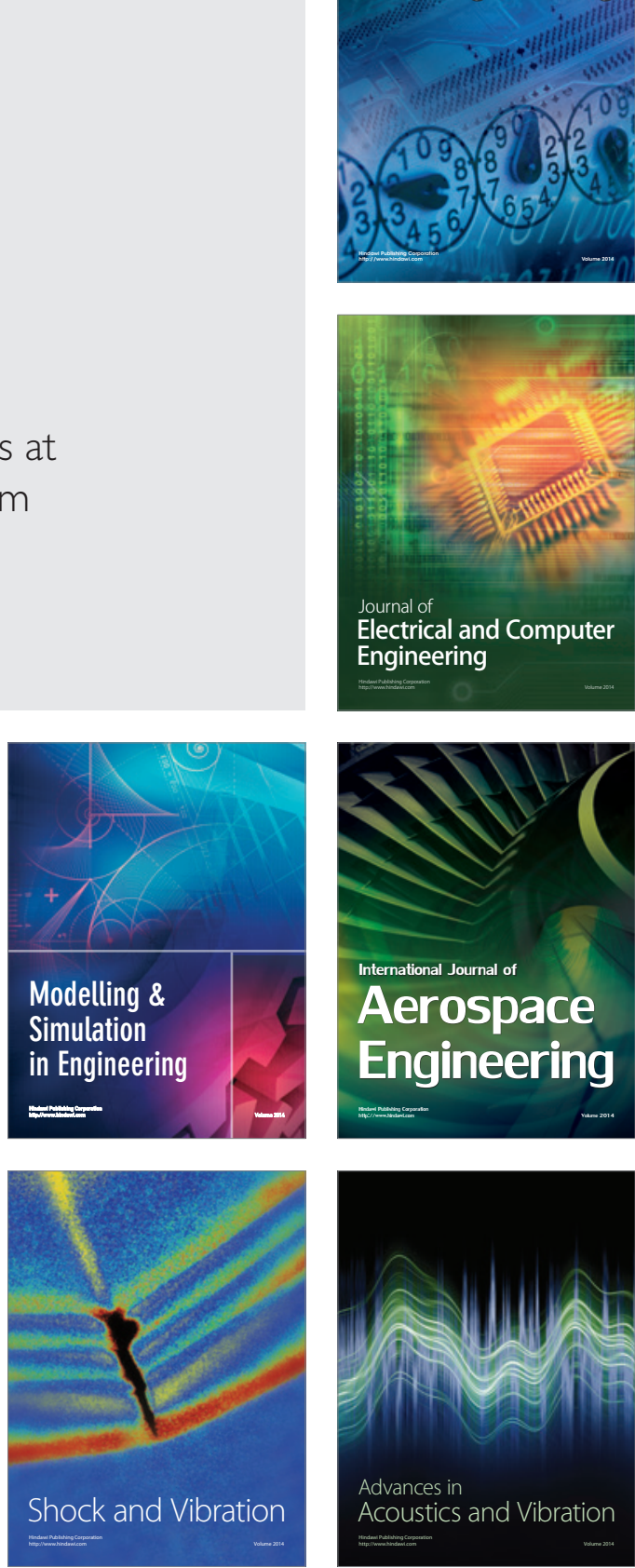